\title{
Ice cream cone sign: reversible ballooning of the trachea due to tracheostomy tube cuff overinflation
}

\section{Ashutosh Sachdeva, ${ }^{1}$ Edward M Pickering, ${ }^{2}$ Robert M Reed, ${ }^{2}$ Carl B Shanholtz ${ }^{1}$}

${ }^{1}$ Department of Pulmonary and Critical Care, University of Maryland, Baltimore, Maryland, USA

${ }^{2}$ Department of Pulmonary and Critical Care Medicine, University of Maryland, Baltimore, Maryland, USA

\section{Correspondence to} Dr Robert M Reed, rreed@medicine.umaryland.edu

Accepted 17 April 2016
CrossMark

\section{To cite: Sachdeva A,} Pickering EM, Reed RM, et al. BMJ Case Rep Published online: [please include Day Month Year] doi:10.1136/bcr-2016-

214625

\section{DESCRIPTION}

A woman in her 80 s with ventilator-dependent respiratory failure due to severe cardiomyopathy and critical illness myopathy was transferred to our hospital after experiencing recurrent episodes of ventricular fibrillation cardiac arrest requiring cardiopulmonary resuscitation. On arrival, there was a significant air leak despite tracheostomy tube (TT) cuff pressures of $50 \mathrm{~cm} \mathrm{H}_{2} \mathrm{O}$ (normal $<25 \mathrm{~cm} \mathrm{H}_{2} \mathrm{O}$ ). Chest radiography revealed what

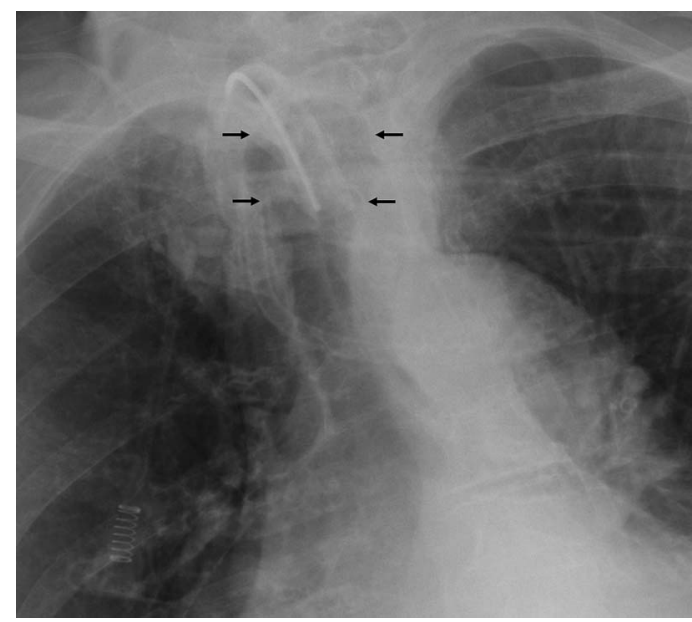

Figure 1 Ice cream cone sign with ballooning of proximal trachea. we term the 'ice cream cone sign' (figure 1 and video 1), consistent with proximal trachea dilation from cuff overinflation. Bronchoscopy demonstrated tracheomegaly (figure 2) at the cuff site, with a normal calibre distal trachea. TT distal end was not coaxial with the tracheal lumen and pointed posteriorly. The TT was exchanged for a longer cuffed TT with the distal end bypassing the ballooned segment and coaxial to the tracheal lumen. The air leak resolved with this intervention



Video 1 Ice cream cone sign with ballooning of proximal trachea.

Figure 2 Tracheostomy tube positioned improperly posteriorly. Arrows indicate area of malacia and dilated tracheal segment.

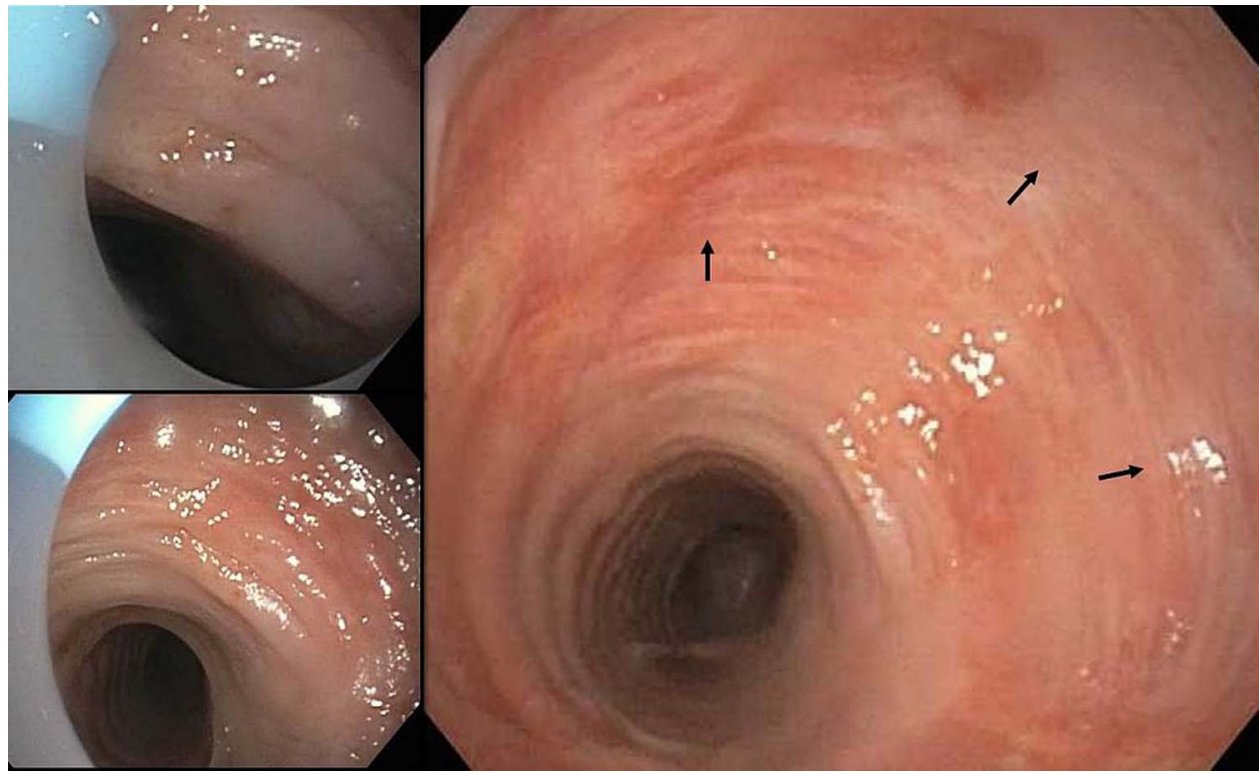




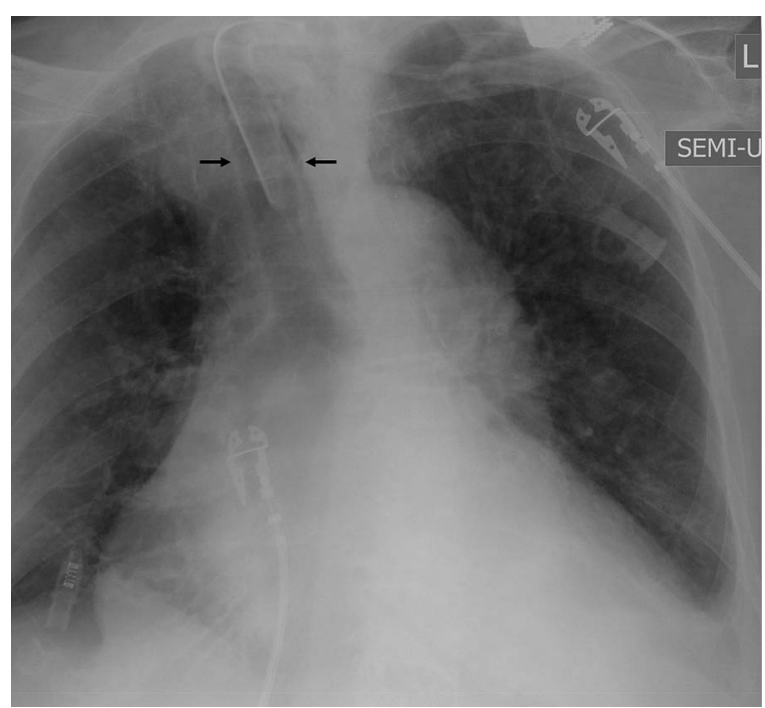

Figure 3 Resolution of tracheal dilation 2 days after tracheostomy exchange.

and chest radiography (figure 3 ) obtained 2 days later revealed a normal tracheal appearance.

Our case is informative in that the 'ballooning' was reversible with decrease in cuff volume and pressures. Others ${ }^{1}{ }^{2}$ have described this to be non-reversible, but cuff pressures were not reported. In our patient, acute decompensation likely necessitated higher levels of ventilator support and resulted in cuff-leak. Subsequently, the cuff balloon was inadvertently hyperinflated to counter air leak. Cuff pressures should be closely monitored, as overinflation could result in ischaemic complications ${ }^{3}$ including tracheomalacia, tracheal stenosis and tracheo-oesophageal fistula. Flexible bronchoscopy provides reliable information about the condition of the trachea and selection of the optimal tracheostomy tube.

\section{Learning points}

- Tracheostomy or endotracheal tube cuff pressures should be kept below $25 \mathrm{H}_{2} \mathrm{O}$ (range $20-30 \mathrm{H}_{2} \mathrm{O}$ ) to prevent ischaemic injury and subsequent airway and airway-oesophageal complications. $^{3}$

- Improperly (non-coaxial) positioning can result in air leaking around an appropriately inflated cuff.

- Bronchoscopy provides reliable information on coaxial positioning of the tracheostomy tube in relation to the trachea.

Contributors All the authors contributed to the manuscript in accordance with ICMJE criteria for authorship.

Competing interests None declared.

Patient consent Obtained.

Provenance and peer review Not commissioned; externally peer reviewed.

\section{REFERENCES}

1 Honig EG, Francis PB. Persistent tracheal dilatation: onset after brief mechanical ventilation with a 'soft-cuff' endotracheal tube. South Med J 1979;72:487-90.

2 Rhodes A, Lamb FJ, Grounds RM, et al. Tracheal dilation complicating prolonged tracheal intubation. Anesthesia 1997:52:70-2.

3 Seeglobin RD, van Hasselt GL. Endotracheal cuff pressure and tracheal mucosal blood flow: endoscopic study of effects of four large volume cuffs. Br Med J (Clin Res Ed) 1984;288:965-8.

Copyright 2016 BMJ Publishing Group. All rights reserved. For permission to reuse any of this content visit

http://group.bmj.com/group/rights-licensing/permissions.

BMJ Case Report Fellows may re-use this article for personal use and teaching without any further permission.

Become a Fellow of BMJ Case Reports today and you can:

- Submit as many cases as you like

- Enjoy fast sympathetic peer review and rapid publication of accepted articles

- Access all the published articles

- Re-use any of the published material for personal use and teaching without further permission

For information on Institutional Fellowships contact consortiasales@bmjgroup.com

Visit casereports.bmj.com for more articles like this and to become a Fellow 